\title{
Insulin action in morbid obesity: a focus on muscle and adipose tissue
}

\author{
Panayota Mitrou, ${ }^{1}$ Sotirios A. Raptis, ${ }^{1,2}$ George Dimitriadis ${ }^{2}$ \\ ${ }^{1}$ Hellenic National Center for Research, Prevention and Treatment of Diabetes Mellitus and its Complications, ${ }^{2} 2^{\text {nd }}$ \\ Department of Internal Medicine, Research Institute and Diabetes Center, Athens University Medical School, "Attikon" \\ University Hospital, Athens, Greece
}

\begin{abstract}
The aim of this review is to summarize the mechanisms underlying insulin resistance in morbid obesity. Glucose regulation by insulin depends on the suppression of endogenous glucose production and stimulation of glucose disposal. In morbid obesity, glucose production by the liver is increased. Moreover, the sensitivity of glucose metabolism to insulin is impaired both in muscle (due to defects in insulin-stimulated glucose utilization and decreased blood flow) and in adipose tissue (due to decreased blood flow). However, recent studies suggest that expanded total fat mass becomes a major consumer of glucose providing a sink for glucose and compensating for insulin resistance. Metabolism and immunity are closely linked. Bearing in mind the crosstalk between inflammatory pathways and the insulin signaling cascade, adipose tissue derived cytokines may represent a link between inflammation and metabolic signals and mediate, at least in part, insulin resistance. Adipose tissue plays a crucial role by buffering daily influx of dietary fat, suppressing the release of non-esterified fatty acids into the circulation and increasing triacylglycerol clearance. However, in morbid obesity there is an impairment of the normal ability of adipose tissue to buffer fatty acids, despite hyperinsulinemia. Lipotoxicity gradually impairs insulin action in the liver and muscle, aggravating insulin resistance.
\end{abstract}

Key words: Adipose tissue, Cytokines, Glucose metabolism, Insulin action, Insulin resistance, Lipid metabolism, Morbid obesity, Muscle

\section{INTRODUCTION}

Obesity is a serious public health problem, with

\section{Address for correspondence:}

Professor George Dimitriadis, MD, DPhil, $2^{\text {nd }}$ Department of

Internal Medicine, Research Institute and Diabetes Center,

Athens University Medical School, "Attikon” University

Hospital, 1 Rimini Street, GR-12462 Haidari, Greece,

Tel.: +30-210-5831255, Fax: +30-210-5326454,

e-mail: gdimi@ath.forthnet.gr and gdimitr@med.uoa.gr

Received 27-07-2012, Accepted 16-03-2013 prevalence increasing rapidly worldwide. The increase in body mass is associated with numerous adverse consequences for health, many of which seem to stem from the associated insulin resistance. ${ }^{1}$ Although there is a clear association between obesity and insulin resistance, the underlying pathophysiological mechanisms of this relationship are complex and obscure.

Glucose regulation by insulin depends on the suppression of endogenous glucose production by the 
liver and stimulation of glucose disposal by muscle and adipose tissue. ${ }^{2}$

Previous studies in morbid obesity ${ }^{3}$ have shown that the sensitivity of glucose metabolism to insulin is impaired in skeletal muscle, which is the most important tissue for insulin-dependent glucose disposal. ${ }^{2}$ This raises the question as to which tissue clears the excess of glucose entering the circulation in obese, non-diabetic subjects.

In a study using $\left[{ }^{18} \mathrm{~F}\right]$-fluorodeoxyglucose-positron emission tomography in moderately obese men, increased fat mass has been shown to provide a sink for glucose, despite adipose tissue insulin resistance. ${ }^{4}$ In morbid obesity, it has been reported that the sensitivity of glucose metabolism to insulin is impaired in adipose tissue, partly due to decreased blood flow, whereas increased total fat mass provides a sink for the excess of glucose and compensates for insulin resistance. ${ }^{3}$

Adipose tissue plays a crucial role by buffering daily influx of dietary fat in the postprandial period, suppressing the release of non-esterified fatty acids (NEFA) into the circulation and increasing triacylglycerol clearance. ${ }^{5}$ However, in obesity, adipose tissue buffering of lipid fluxes is impaired through defects in the ability of adipose tissue to respond rapidly to the dynamic situation in the postprandial period. ${ }^{5}$ Previous studies $^{6}$ have shown that the plasma concentration and rate of appearance of fatty acids are reduced by insulin less rapidly in obese subjects than in those of normal body weight, whereas in recent studies ${ }^{7,8}$ examining adipocytes isolated from obese insulin resistant subjects in vitro under fasting conditions, hormone-sensitive lipase (HSL) and adipose triglyceride lipase (ATGL) protein expression have been found to be decreased. As a result, the extra-adipose tissues are exposed to excessive fluxes of lipid fuels and accumulate these in the form of triacycglyrelol, leading to insulin resistance. ${ }^{5}$

Metabolism and immunity are closely linked. Adipose tissue releases a significant number of cytokines originating from either mature adipocytes or other cells, such as peripheral blood mononuclear cells and macrophages infiltrating adipose tissue. Obesity is associated with a state of aberrant immune activity and increased risk for associated inflammatory diseases, including atherosclerosis, diabetes and fatty liver disease. The high level of coordination of inflammatory and metabolic pathways is highlighted by the overlapping biology and function of macrophages and adipocytes in obesity. ${ }^{9}$ Several adipose tissue-derived cytokines, including interleukin-6 (IL-6), tumour necrosis factor $\alpha$ (TNF- $\alpha$ ) and resistin, have been implicated in the impairment of insulin sensitivity, while others (such as leptin and adiponectin) have been shown to have an insulin-sensitizing effect. ${ }^{10}$

The aim of this review is to summarize the mechanisms underlying insulin resistance in morbid obesity in peripheral tissues, focusing on the crosstalk between organs regulating energy homeostasis, insulin sensitivity, lipid metabolism and the immune system. Moreover, this review highlights the role of decreased blood flow rates in the impairment of glucose disposal and lipid metabolism in peripheral tissues, as well as the role of expanded fat mass functioning as a sink for glucose.

For this purpose, we performed a Medline search using a combination of terms: morbid obesity, glucose metabolism, insulin resistance, insulin secretion, glucose uptake, glucose disposal, glucose production, skeletal muscle, adipose tissue, blood flow, lipid metabolism, triglycerides, non-esterified fatty acids and cytokines. During the first phase, Medline search resulted in 3652 citations. After excluding citations that were referred to more than one time, 2067 citations were left. Focusing on human studies that could be eligible for the purposes of this review, 79 papers were finally selected and cited.

\section{INSULIN SECRETION}

In obesity, plasma insulin levels and their response to a carbohydrate load are increased. Some people can maintain compensatory hyperinsulinemia throughout their life and keep their blood glucose levels within normal range (Figure 1A, 1B). ${ }^{3}$ This compensation involves mechanisms that increase the sensitivity of the beta cell to a glucose stimulus resulting in increased insulin secretion. ${ }^{11}$ The exact pathophysiological mechanisms leading to increased beta-cell secretory activity are still uncertain. Recently it has been proposed that insulin hypersecretion in morbid obesity is partly adaptive to insulin resistance and partly due to obesity itself. ${ }^{12}$ As regards substrates, increased non- 

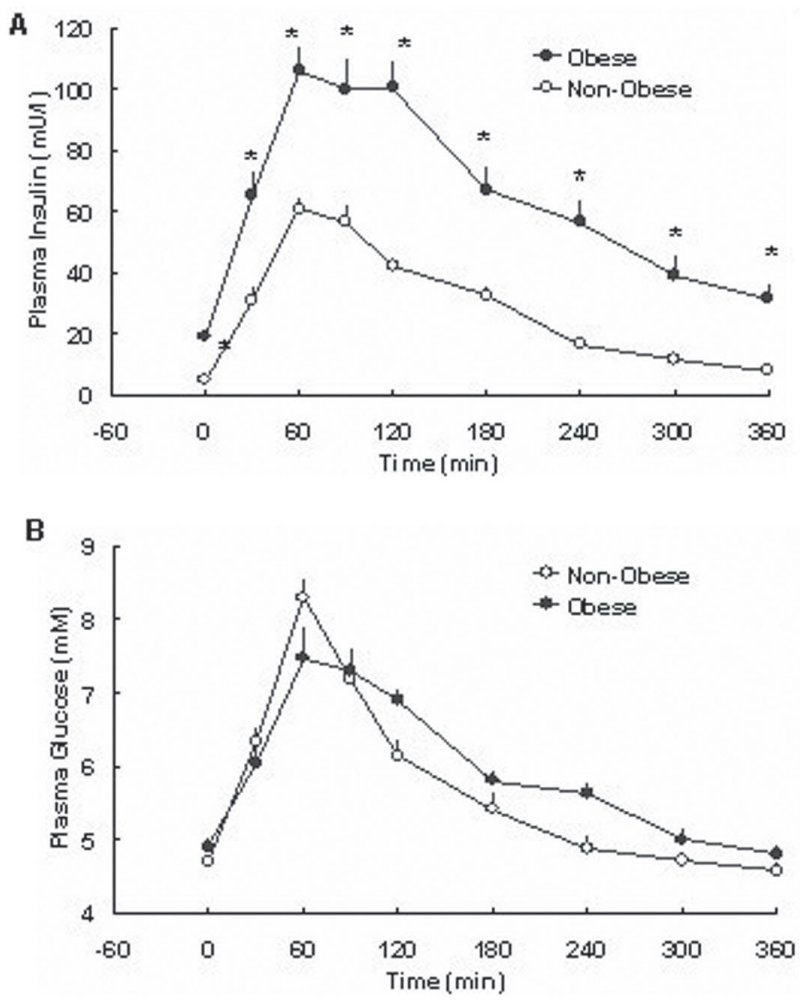

Figure 1. Arterial plasma glucose (A), and insulin (B) levels in obese and non-obese subjects after a meal [differences between groups were tested with non-paired t-test $(*: \mathrm{p}<0.05)]$. [Mitrou P, et al, 2009 J Clin Endocrinol Metab 94: 2958-2961 with permission from The Endocrine Society (Copyright 2009)].

esterified fatty acid levels may enhance insulin release in humans, although long-term exposure to elevated fatty acids may inhibit insulin biosynthesis and increase the proinsulin:insulin ratio of secretion. ${ }^{13}$ Humoral or neural signals originating in the central nervous system may also be responsible for a sustained upregulation of beta-cell function. ${ }^{14,15}$ Thus, under fasting or fed conditions, the hyperinsulinemia of obesity mainly depends on increased insulin secretion. However, in patients with more marked basal hyperinsulinemia and during intense stimulation of insulin secretion, a reduction in hepatic insulin clearance may also contribute to a more pronounced increase in circulating insulin levels. ${ }^{12,16}$ Insulin clearance is mediated by the internalization of the bound insulin to its receptor and subsequent degradation of insulin and a fraction of the receptor. The reduced plasma insulin clearance can be attributed to the downregulation of the insulin receptor number which is evident in hyperinsulinemic states. The reduced plasma insulin clearance can be attributed to decreased hepatic extraction, related to insulin resistance.

Previous studies examining 24hour secretory insulin profiles show that in obese non-diabetic subjects the dynamic aspects of beta-cell function are intact, although set at a higher level. ${ }^{11,12}$ Thus in obesity, the regulatory mechanisms influencing secretory profiles are still operative, although functioning beta-cell mass is enhanced.

In other cases, especially in genetically predisposed individuals, the important dynamic properties of the feedback loop linking insulin secretion and glucose are impaired and the ability of the pancreatic islets to sustain high rates of insulin production gradually decreases. At first, insulin levels may fall to a little less than necessary, leading to mild hyperglycemia (mainly in the postprandial period). If insulin levels fall further, clinically evident diabetes develops.

However, these alterations in beta-cell function can, in many cases, be reversed; previous studies have shown that in morbidly obese subjects with or without type 2 diabetes, defects in insulin secretion can be improved after weight loss following bariatric surgery. ${ }^{17-19}$ Interestingly, malabsorptive bariatric surgery in morbidly obese subjects has been shown to correct both the insulin hypersecretion and the insulin resistance at a time when body mass index was still high. With continued weight loss over a 2-year period, moderately obese subjects became supersensitive to insulin and, correspondingly, insulin hyposecretors. ${ }^{12}$

\section{INSULIN ACTION IN PERIPHERAL TISSUES}

\section{Endogenous glucose production}

In obese subjects, insulin action in the liver is impaired. ${ }^{20,21}$ Hepatic insulin resistance in obesity can be attributed to impaired insulin-induced suppression of both gluconeogenesis and glycogenolysis. ${ }^{22}$ These abnormalities persist when glucagon secretion is inhibited by somatostatin, indicating that factors other than hyperglucagonemia impair the ability of insulin to suppress gluconeogenesis and glucogenolysis. ${ }^{22}$

The relative contribution of these abnormities to endogenous glucose production has been investi- 
gated by Chevalier et al:;3 in this study, obesity was associated with an increase in both the fractional and absolute contribution of gluconeogenesis to glucose production, which could be attributed to increased protein turnover rates and insulin resistance. High protein catabolism and insulin resistance of glucose, lipid and protein metabolism result in increased supply of gluconeogenic precursors (aminoacids) ${ }^{23}$ and stimulators (non-esterified fatty acids) ${ }^{2,22}$ to the liver that trigger gluconeogenesis.

\section{Glucose utilization in skeletal muscle and adipose tissue}

Skeletal muscle is considered as the most important tissue for insulin-mediated glucose uptake in vivo, ${ }^{2,24}$ whereas adipose tissue is not a major consumer of glucose in normal weight subjects..$^{25,26}$

Moreover, insulin affects vascular endothelium and increases muscle and adipose tissue blood flow by increasing vasodilation and capillary recruitment. ${ }^{2}$ Impairment of this mechanism in insulin-sensitive tissues may partly account for insulin resistance in insulin resistance states such as obesity ${ }^{3,27}$ and type 2 diabetes. ${ }^{28}$

In morbidly obese subjects glucose disposal has been found to be decreased. A major defect contributing to impaired insulin action in morbid obesity, as studied with the euglycemic-hyperinsulinemic clamp technique, is reduced glucose transport activity in skeletal muscle..$^{29}$ After weight loss, glucose disposal increased markedly; this improvement can be attributed to enhanced glucose transporters (GLUT4) translocation and/or activation. ${ }^{29}$

Further studies in morbidly obese subjects, using the arteriovenous difference technique across the forearm muscles, ${ }^{3,30}$ have revealed that glucose disposal as well as forearm blood flow are decreased postprandially despite hyperinsulinemia (Figure 2A, 2B). In addition, fractional glucose extraction (which is independent of blood flow) is also markedly decreased in the forearm muscles. These studies suggest that in morbid obesity, the resistance of glucose disposal to insulin in skeletal muscle is due to defects in both insulin-stimulated cellular glucose extraction and decreased blood flow rates. As a result, in obesity, insulin resistance of glucose uptake in skeletal muscle cannot be ameliorated only by enhancing endothelium-dependent blood flow. ${ }^{31}$

Glucose disposal and blood flow rates in the adipose tissue have also been found decreased in morbid obesity (Figures 2C, 2D). ${ }^{3}$ However, fractional glucose extraction was not impaired in the adipose tissue, suggesting that the resistance of glucose disposal to insulin in adipose tissue could be accounted for, at least in part, by the impairment in blood flow. ${ }^{3}$ In accordance with these findings, a study in moderately obese men, using euglycemic hyperinsulinemic clamp technique and $\left[{ }^{15} \mathrm{O}\right]$-labeled water, showed that insulin stimulated glucose uptake and perfusion were impaired in all fat depots. ${ }^{30}$

Taking into consideration these studies showing that in morbid obesity the sensitivity of glucose metabolism to insulin is impaired in both skeletal muscle and adipose tissue, a reasonable question arises. Which tissue clears the excess of glucose entering the circulation in obese, non-diabetic subjects?

This question was addressed in a recent study which showed that although adipose tissue glucose disposal - expressed as per unit of adipose tissue - is decreased, adipose glucose uptake multiplied by tissue mass and expressed as per total fat mass is increased in morbidly obese compared to non-obese subjects. ${ }^{3}$ In this study estimated total muscle glucose uptake in non-obese subjects was equivalent to approximately $41 \%$ of meal carbohydrate ingested, whereas wholebody adipose tissue uptake was only $7 \%$, suggesting that adipose tissue is not a major consumer of glucose in non-obese subjects. In contrast, in the morbidly obese group, total glucose uptake was increased (compared to the non-obese group) in the adipose tissue (approximately $17 \%$ of the ingested carbohydrate) and was comparable to the percentage of the ingested carbohydrate taken up by muscle (19\%), suggesting that expanded fat mass in morbid obesity can provide a sink for the excess of glucose entering the circulation. In accordance with the studies in morbid obesity, a recent study using the $\left[{ }^{18} \mathrm{~F}\right]$-FDG-PET method has shown that adipose tissue contribution to whole-body glucose uptake is also increased in moderately obese compared to non-obese subjects. ${ }^{4}$

In summary, in morbid obesity the sensitivity of glucose metabolism to insulin is impaired in both 

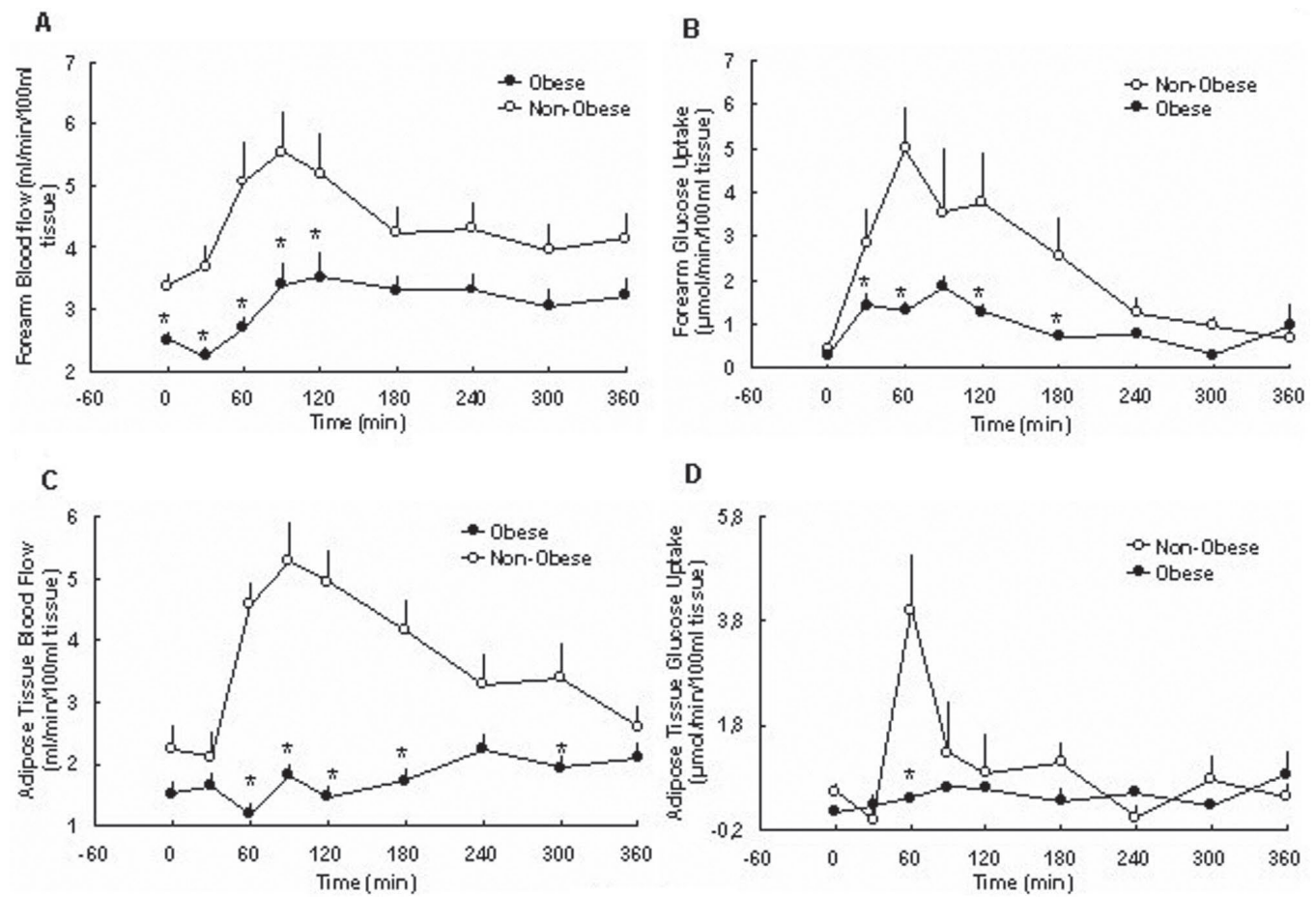

Figure 2. Blood flow (A) and glucose uptake (per 100ml tissue) (B) in the forearm muscles and blood flow (C) and glucose uptake (per 100ml tissue) (D) in the adipose tissue in obese and non-obese after a meal [differences between groups were tested with nonpaired t-test $(*: \mathrm{p}<0.05)$ ]. [Mitrou P, et al, 2009 J Clin Endocrinol Metab 94: 2958-2961 with permission from The Endocrine Society (Copyright 2009)].

skeletal muscle and adipose tissue. More specifically, in skeletal muscle due to defects in insulin-stimulated glucose utilization and decreased blood flow rates, and in adipose tissue mainly due to decreased blood flow. However, expanded total fat mass provides a sink for the excess of glucose and compensates for insulin resistance. On the other hand, further increase in obesity or co-existence of other factors (genetic predisposition, endocrinopathies, drugs that interfere with glucose metabolism, etc) can lead to rupture of the compensatory mechanism and development of overt diabetes.

\section{Lipid metabolism in adipose tissue}

The buffering of fatty acids by insulin is mainly regulated by the suppression of lipolysis and NEFA release from the adipose tissue via a decrease in the activity of hormone-sensitive lipase (HSL) and adipose triglyceride lipase (ATGL), ${ }^{5,32}$ and the increase of triglyceride clearance through an increase in the activity of lipoprotein lipase (LPL). ${ }^{5}$

In obesity, adipose tissue function is impaired so that buffering is less effective. In both moderate ${ }^{6}$ and morbid obesity, ${ }^{33}$ plasma triglyceride levels are elevated both in the fasting and the postprandial state, suggesting a lower triglyceride turnover (Figure 3A). This can be attributed to a decreased rate of removal by the adipose tissue due to decreased LPL activity, despite hyperinsulinemia (Figures 3B, 3C). Given that the arteriovenous differences of triglycerides (which are independent of blood flow rates) across the adipose tissue have been found to be similar between obese and non-obese subjects, low LPL activity in the obese subjects could be accounted for, at least in part, by decreased blood flow rates. ${ }^{33}$

Fasting plasma NEFA levels are not increased in morbid obesity, despite the excess of fat mass. ${ }^{33,34}$ However, previous studies show that postprandially, plasma NEFA levels are suppressed less in the obese compared to the non-obese subjects (Figure 4A). ${ }^{33}$

Lipid fluxes have been examined by the arteriovenous difference technique in a study performed in moderately obese men; this study showed impaired 

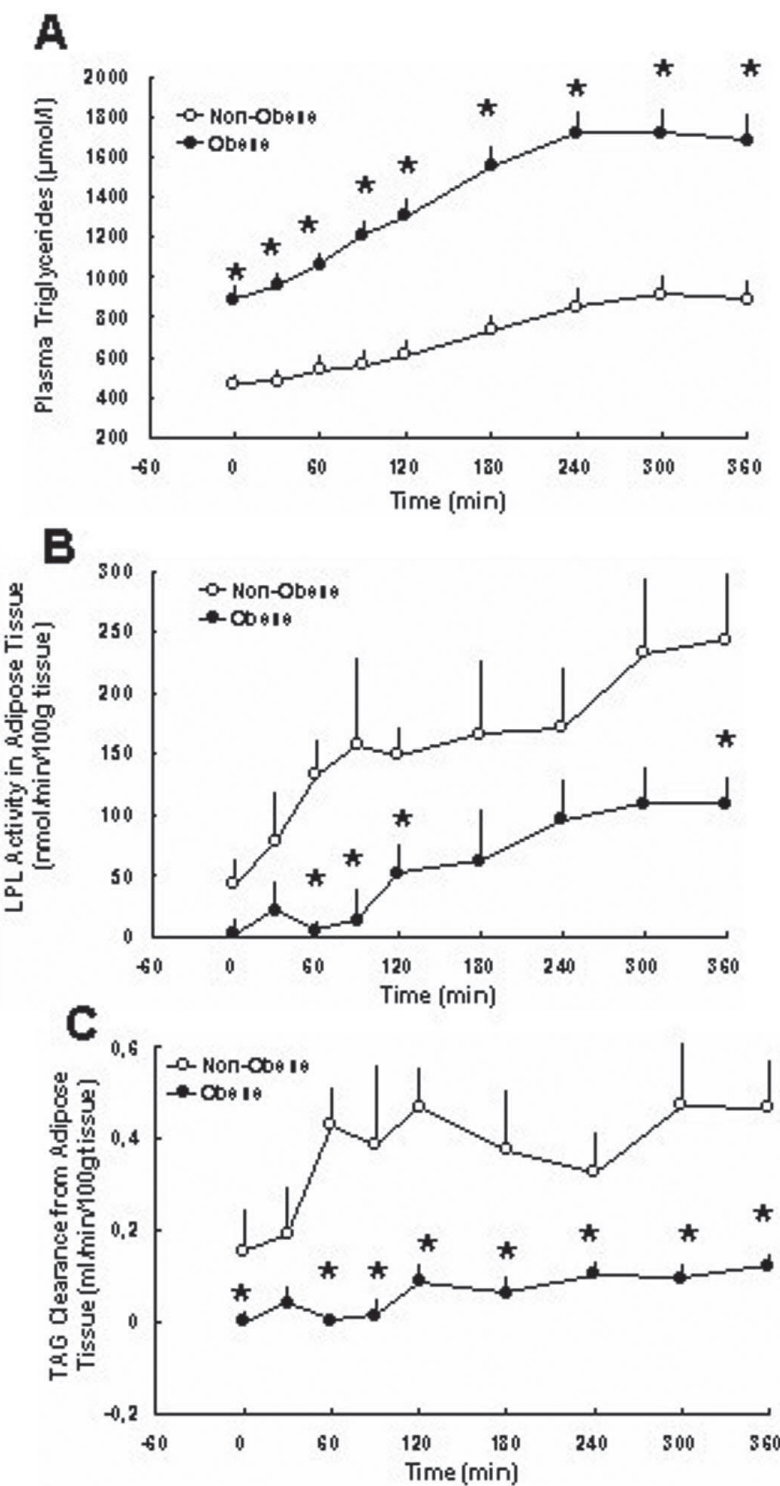

Figure 3. Arterial plasma triglyceride levels (A), LPL activity (B) and triglyceride (TAG) clearance from adipose tissue $(\mathrm{C})$ in obese vs non-obese after a meal $\left({ }^{*} \mathrm{p}<0.05\right)$. [Mitrou $\mathrm{P}$, et al, 2010 Int J Obes (Lond) 34: 770-774].

suppression of HSL, resulting in abnormal NEFA release per $100 \mathrm{~g}$ of adipose tissue. ${ }^{6}$

In morbid obesity, although plasma NEFA levels have been found increased in the obese (compared to the non-obese) subjects, the rates of NEFA fluxes and HSL-derived glycerol output per $100 \mathrm{~g}$ of adipose tissue were not different between the two groups (Figures 4B, 4C). However, NEFA flux multiplied by tissue mass and expressed as per total fat mass was

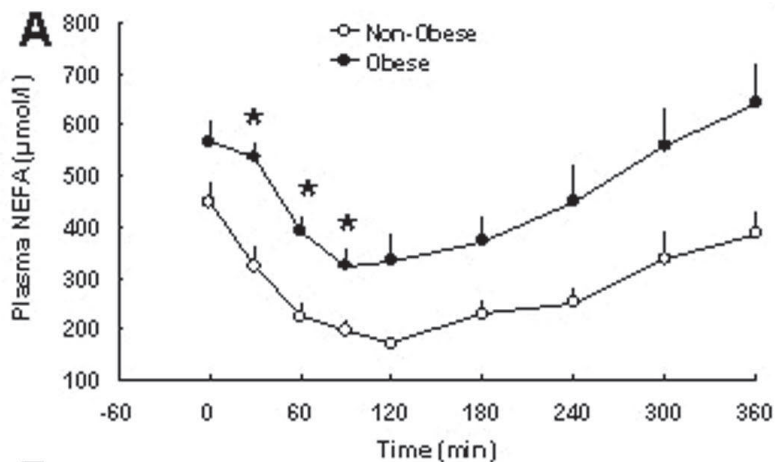

B
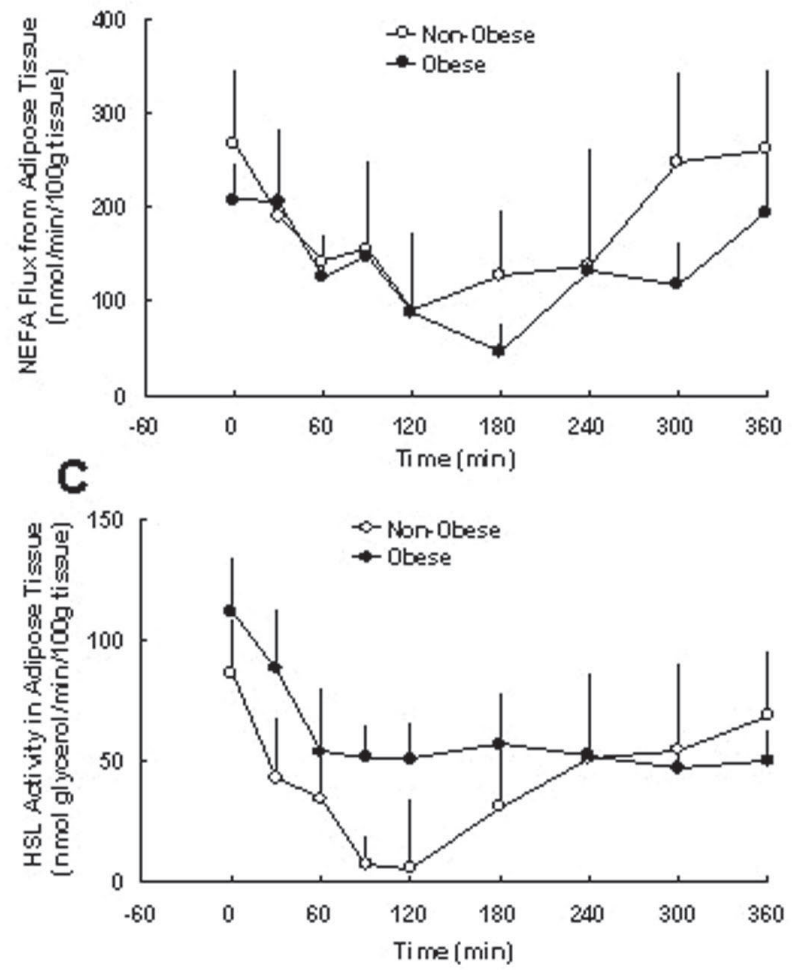

Figure 4. Arterial plasma NEFA levels (A), NEFA flux from $100 \mathrm{~g}$ adipose tissue (B) and adipose tissue HSL activity $(\mathrm{C})$ in obese vs non-obese after a meal $\left({ }^{*} \mathrm{p}<0.05\right)$. [Mitrou $\mathrm{P}$, et al, 2010 Int J Obes (Lond) 34: 770-774].

increased in morbidly obese compared to non-obese subjects, suggesting that the increased circulating NEFA levels could be explained by the excess of fat mass in morbid obesity. ${ }^{33}$

Another possible explanation for the increased levels of NEFA in the circulation in obesity could be a defect in the adipocyte uptake of fatty acids liberated from plasma triacylglycerol by LPL. It is well known that LPL in the adipose tissue capillar- 
ies generates a surplus of fatty acids, a proportion of which will be taken up by adipocytes for reesterification and storage as triacylglycerol. ${ }^{5}$ A proportion of the LPL-generated fatty acids, however, always enters the plasma as NEFA. ${ }^{5}$ Total arterial plasma NEFA levels are composed of both the rate of appearance of NEFA derived from tissue stores and of NEFA appearing from intravascularly hydrolyzed triglycerides that escape from tissue uptake. In morbidly obese subjects adipose tissue NEFA reesterification rates have been found decreased, ${ }^{33}$ supporting the hypothesis that a defect in the adipocytes uptake of fatty acids liberated from plasma triacylglycerol by LPL could contribute to increased plasma NEFA levels. This is in accordance with studies in moderately obese subjects using the euglycaemic clamp technique under non-equilibrium tracer conditions, suggesting that impaired insulin-induced suppression of the rate of appearance of NEFA could be attributed to an enhanced escape of NEFA uptake after intravascular triglyceride hydrolysis. ${ }^{35}$

Another possible explanation for the excess of NEFAs in morbid obesity lies in the liver. It is well known that the postprandial increase in insulin can acutely inhibit VLDL secretion. ${ }^{5}$ However, hepatic insulin resistance in obesity might prevent such inhibition and thus could explain, in part, postprandial hyperlipidemia. ${ }^{6}$

In conclusion, in morbid obesity plasma triglyceride levels are increased following a defect in the postprandial dynamic adjustment of LPL (partly caused by blunted adipose tissue blood flow). In addition, postprandially, there is an impairment of the normal ability of adipose tissue to buffer fatty acids excess, despite hyperinsulinemia.

Under these conditions, all tissues are chronically exposed to very high concentrations of non-esterified fatty acids and triacylglycerol. The toxic effect of excess lipid products, known as "lipotoxicity", gradually impairs insulin action on the liver and muscle, aggravating insulin resistance. Hyperlipidemia leads to increased uptake of lipids by muscle cells in a similar and parallel fashion as in nonalcoholic fatty liver disease. ${ }^{36}$ Fat accumulates in the skeletal muscle of morbidly obese individuals, both between fibers and within myocytes. It has been hypothesized that the accumulation of active fatty acid metabolites, such as acyl CoA, ceramides and diacylglycerol, rather than the accumulation of triglycerides stimulate inflammatory cascades and inhibit insulin signalling. ${ }^{37}$ Weight loss leads to a reduction in intramuscular lipid content, which in turn is related to an improvement in insulin action. ${ }^{38,39}$ Interestingly, intramyocellular lipid depletion after biliopancreatic diversion (an operation that induces predominant lipid malabsorption) has been shown to induce a normal metabolic state (in terms of insulin-mediated whole-body glucose disposal, intracellular insulin signaling and circulating leptin levels) even before pronounced weight loss. ${ }^{40,41}$

\section{ROLE OF CYTOKINES AND ADIPOKINES ON INSULIN ACTION}

The circulating levels of many cytokines increase with the enlargement of fat mass. In obesity, adipose tissue becomes inflamed, both via increased production of inflammatory cytokines by mature adipocytes and through infiltration of adipose tissue by macrophages $;{ }^{9}$ indeed, it has been suggested that most adipokines, in morbidly obese humans, are derived from nonfat cells. ${ }^{42,43}$ These cytokines might act locally in an auto-/paracrine manner or might exert systemic effects on metabolism, immunology and endocrinology. ${ }^{44}$

\section{1. $I L-6$}

IL-6 is released by adipose tissue (both visceral and subcutaneous) and has been implicated in regulating insulin signaling in peripheral tissues. ${ }^{45-49}$ Other reports indicate that IL- 6 could be a myokine, defined as a cytokine which is produced and released by contracting skeletal muscle fibres, exerting its effects in other organs of the body. ${ }^{50,51}$

The circulating levels of IL-6 increase with the enlargement of fat mass. Indeed, in morbid obesity both arterial and subcutaneous venous IL-6 levels have been found increased compared with the nonobese subjects..$^{52,53}$

Moreover, recent studies suggest that subcutaneous adipose tissue-derived IL- 6 could be associated with the impairment of insulin sensitivity in the skeletal muscle of morbidly obese subjects. ${ }^{52}$ In these studies, both arterial and subcutaneous venous 
IL-6 levels were negatively associated with forearm glucose uptake, suggesting that IL-6 released from the subcutaneous adipose tissue could act, at least in part, as an endocrine mediator of insulin resistance in the forearm muscles of morbidly obese subjects. The association between the IL-6 levels and the forearm glucose uptake remained significant after inclusion of total fat mass as a covariate in the statistical analysis, indicating that this association is not confounded by fat mass, as has been previously proposed.$^{54}$

In accordance with these studies, previous experiments in vivo have demonstrated a strong relationship between IL- 6 and whole body insulin resistance determined by an intravenous glucose tolerance test. ${ }^{55}$ Other studies ex vivo showed that chronically elevated IL-6 levels in mice are associated with impaired insulin-stimulated glucose uptake by the skeletal muscles, probably due to decreased amounts of GLUT4 glucose transporters. ${ }^{56}$

Interestingly, weight loss, obtained through lifestyle intervention (hypocaloric diet and daily moderate exercise), induced a reduction in circulating IL-6 levels in addition to an improvement in the metabolic status. ${ }^{53}$ Besides the reduction in plasma values, IL-6 expression was also reduced after the lifestyle intervention in adipose tissue and skeletal muscle biopsies. ${ }^{53}$

\section{Leptin}

Leptin is considered as an "adipostat" which represses food intake and promotes energy expenditure. Moreover, leptin has been shown to improve hepatic and skeletal muscle insulin sensitivity and to modulate pancreatic $\beta$-cell function in normal weight subjects. ${ }^{10}$

Although leptin was first regarded as a promising anti-obesity drug, administration of recombinant leptin in subjects with excess body weight was not efficient in terms of weight $\operatorname{loss}^{57}$ due to central leptin resistance. Indeed, obesity is characterized by "leptin resistance" defined as a diminished response to the anorexigenic and insulin-sensitizing effects, despite high circulating leptin levels. ${ }^{10}$

Evidence derived from animal and human studies suggests that the ability of leptin to stimulate fatty acids oxidation in muscle is impaired in obesity. If the above assumption is correct, leptin may be an initiating factor in the accumulation of intramuscular lipids and the ensuing development of insulin resistance. ${ }^{58,59}$ Although this hypothesis is intriguing, further studies are needed to identify if leptin resistance leads to, aggravates or results from insulin resistance.

Morbid obesity has been associated with an excessive increase of both arterial and subcutaneous venous leptin levels. ${ }^{52}$ However, despite increased secretion of leptin by the subcutaneous adipose tissue, leptin levels were not correlated to the sensitivity of glucose metabolism to insulin in muscle, suggesting that the insulin-sensitizing effects of leptin are lost in morbid obesity. ${ }^{52}$

\section{TNF- $\alpha$}

In morbidly obese subjects TNF- $\alpha$ levels are increased compared to non-obese subjects. ${ }^{52,53}$ In contrast to experiments performed in adipocytes isolated and incubated in vitro showing increased TNF- $\alpha$ secretion from the subcutaneous adipose tissue, ${ }^{55}$ in vivo studies using the arteriovenous difference technique, in moderately ${ }^{60}$ and morbidly ${ }^{52}$ obese subjects, show that TNF- $\alpha$ is not substantially secreted by this depot. Recently, it has been proposed that TNF- $\alpha$ is a paracrine factor released mainly by mast cells, macrophages and other mononuclear cells that are involved in the insulin resistance in obesity. ${ }^{48,58}$

Conflicting data exist regarding the role of TNF- $\alpha$ in the regulation of glucose metabolism. In previous studies, TNF- $\alpha$ levels have been associated with insulin resistance; ${ }^{61}$ in contrast, infusion of TNF- $\alpha$ neutralizing antibodies in obese subjects or patients with type 2 diabetes did not improve insulin sensitivity ${ }^{62,63}$ In morbid obesity, arterial and subcutaneous venous TNF- $\alpha$ levels, although increased compared to lean subjects, are not correlated to the sensitivity of glucose metabolism to insulin..$^{52}$

However, it has previously been suggested that TNF- $\alpha$ production is a counter-regulatory mechanism that acts in various ways to prevent further body-fat deposition. A possible mechanism by which TNF- $\alpha$ can limit fat depot enlargement is by modulating LPL activity; indeed, adipose tissue LPL activity has been found to be negatively related to TNF- $\alpha$ expression. ${ }^{64}$ Moreover, previous studies identified a positive relationship between the expression of TNF- $\alpha$ and adipocyte leptin production. As a result, TNF- $\alpha$ 
may also be involved in regulating fat stores through leptin, which has been shown to play a central role in regulating energy balance. ${ }^{64}$

\section{Resistin}

Recent studies suggested that resistin levels may be associated with obesity and insulin resistance, ${ }^{65,66}$ whereas other studies failed to identify changes of resistin levels in these conditions. ${ }^{67,68}$

In morbid obesity, resistin levels have been found increased compared to the non-obese group and negatively correlating with forearm glucose uptake. ${ }^{52}$ Given that there was no secretion of resistin by the subcutaneous adipose tissue, studied with the arteriovenous difference technique, it is possible that resistin produced by other tissues (e.g. visceral adipose tissue) or cells (e.g. peripheral mononuclear cells) interfere with insulin action in skeletal muscle. ${ }^{69,70}$

\section{Adiponectin}

It has been shown that there is a wide distribution of adiponectin secretion rates as well as a substantial variation in adiponectin secretion from the specific adipose tissue depots. ${ }^{71}$ Previous in vitro studies have demonstrated secretion of adiponectin from both visceral and subcutaneous adipose tissue. ${ }^{44,72}$

In morbid obesity adiponectin has been found to be decreased compared to lean subjects..$^{53}$ Of specific interest is the observation that low plasma adiponectin and mRNA levels in adipose tissue biopsies from subjects with severe obesity were not related to the increase in adipose tissue macrophage infiltration but may rather be the result of inhibitory effects of other adipokines (such as IL-6 and TNF- $\alpha$ ) released from the macrophages resident in the adipose tissue. ${ }^{73}$

Adiponectin levels correlate negatively with body fat, fasting plasma insulin, abnormal oral glucose tolerance and correlate positively with glucose disposal during a euglycemic insulin clamp. ${ }^{74-78}$ However, weight loss through lifestyle intervention increases plasma adiponectin levels and improves the metabolic status. ${ }^{53}$

Interestingly, it has previously been suggested that adiponectin is an important cytokine antagonizing factors (such as obesity, hepatic lipid deposition and inflammation), leading to systemic insulin resistance. Therefore, the inability to sustain elevated adiponectin levels during times of excess caloric intake can lead to ectopic fat accumulation in liver and associated insulin resistance. ${ }^{79}$

\section{CONCLUDING REMARKS (Figure 5)}

Obesity-associated insulin resistance is manifested by increased endogenous glucose production by the liver and defects in glucose and lipid metabolism in skeletal muscle and adipose tissue.

Hepatic insulin resistance in obesity can be attributed to impaired insulin-induced suppression of gluconeogenesis and, to a lesser extent, of glycogenolysis. $^{22,23}$

In peripheral tissues, the sensitivity of glucose metabolism to insulin is impaired both in muscle (due to defects in insulin-stimulated glucose utilization and decreased blood flow) and in adipose tissue (mainly due to a defect in vascular vasodilatation and decreased blood flow). However, expanded adipose tissue fat mass becomes a major consumer of glucose providing a sink for glucose in morbidly obese nondiabetic subjects. ${ }^{3}$

Considering the crosstalk between inflammatory pathways and insulin signaling cascade, it is also possible that adipokines and inflammatory cytokines contribute to the development of insulin resistance in the skeletal muscle of morbidly obese subjects.

As far as lipid metabolism is concerned, in morbid obesity plasma triglyceride levels are increased following a defect in the postprandial dynamic adjustment of LPL (partly caused by decreased adipose tissue blood flow) ${ }^{33}$ In addition, postprandially, there is an impairment of the normal ability of adipose tissue to buffer fatty acids excess, despite hyperinsulinemia. ${ }^{33}$ Under these conditions, all tissues are chronically exposed to very high concentrations of non-esterified fatty acids and triacylglycerol. The toxic effect of increased levels of non-esterified fatty acids, known as "lipotoxicity" gradually impairs insulin action on the liver and muscle, aggravating insulin resistance. As long as the pancreatic beta cell can adapt to insulin resistance in peripheral tissues with an appropriate increase in insulin secretion, normal glucose homeostasis can be maintained. However, an additional effect of lipotoxicity on the islet $\beta$-cells 


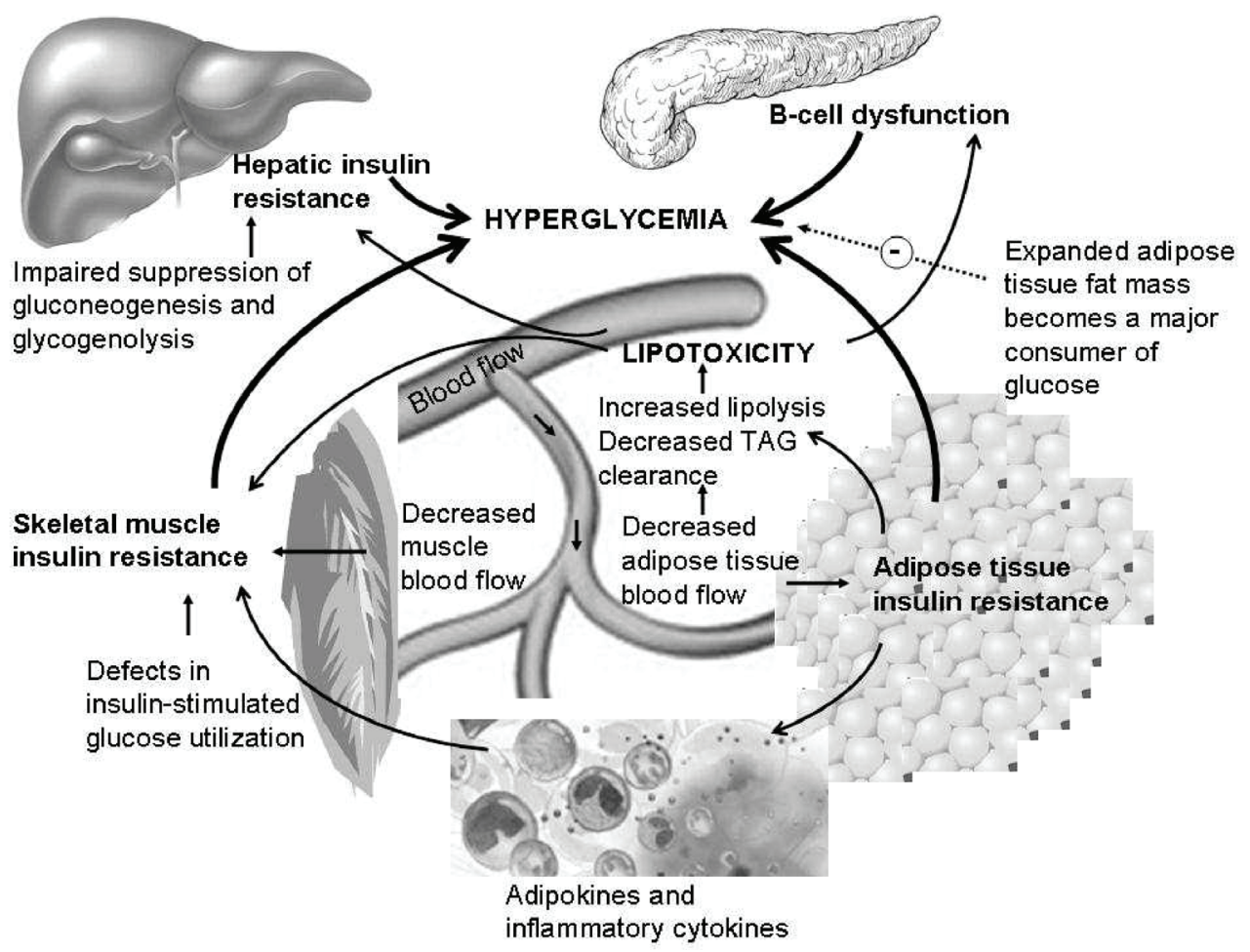

Figure 5. Pathophysiology of insulin action in morbid obesity (TAG: triglycerides, NEFA: non-esterified fatty acids).

may result in a defect in insulin secretion. As soon as the beta cell capacity for adaptation is exceeded, glucose tolerance deteriorates and overt diabetes mellitus eventually develops.

\section{Disclosure statement}

The authors have nothing to declare.

\section{REFERENCES}

1. Maratos-Flyer E, Flyer JS 2005 Obesity. In: Kahn CR, Weir GC, King GL, Jacobson AM, Moses AC, Smith RL (eds) Joslin's Diabetes Mellitus, Lippincott Williams and Wilkins, Philadelphia, Baltimore, New York, London, Buenos Aires, Hong Kong, Sydney, Tokyo; pp, 533-546.

2. Dimitriadis G, Mitrou P, Lambadiari V, Maratou E, Raptis SA, 2011 Insulin effects in muscle and adipose tissue. Diabetes Res Clin Pract 93: Suppl 1: 52-59.

3. Mitrou P, Boutati E, Lambadiari V, et al, 2009 Rates of glucose uptake in adipose tissue and muscle in vivo after a mixed meal in women with morbid obesity. $\mathrm{J}$ Clin Endocrinol Metab 94: 2958-2961.

4. Virtanen K, Lozzo P, Hallsten K, et al, 2005 Increased fat mass compensates for insulin resistance in abdominal obesity and type 2 diabetes. Diabetes 54: 2720-2726.

5. Frayn K, 2002 Adipose tissue as a buffer for daily lipid flux. Diabetologia 45: 1201-1210.

6. Coppack S, Evans R, Fisher R, et al, 1992 Adipose tissue metabolism in obesity: lipase action in vivo before and after a mixed meal. Metabolism 41: 264-272.

7. Jocken JW, Langin D, Smit E, et al, 2007 Adipose triglyceride (ATGL) and hormone-sensitive lipase (HSL) protein expression is decreased in the obese insulin resistant state. J Clin Endocrin Metab 92: 2292-2299.

8. Langin D, Dicker A, Tavernier G, et al, 2005 Adipocyte lipases and defect of lipolysis in human obesity. Diabetes 54: 3190-3197.

9. Wellen K, Hotamisligil G, 2005 Inflammation, stress, and diabetes. J Clin Invest 115: 1111-1119.

10. Rabe K, Lehrke M, Parhofer KG, Broedl UC, 2008. Adipokines and insulin resistance. Mol Med 14: 741-751.

11. Polonsky KS, 2000 Dynamics of insulin secretion in obesity and diabetes. Int J Obes 24: Suppl 2: 29-31.

12. Camastra S, Manco M, Mari A, et al, 2005 Beta-cell function in morbidly obese subjects during free living. Long-term effects of weight loss. Diabetes 54: 2382-2389.

13. Grill V, Qvigstad E 2000 Fatty acids and insulin secretion. Br J Nutr 83: Suppl 1: 79-84.

14. Woods SC, Porte D Jr, Bobbioni E, et al, 1985 Insulin: its relationship to the central nervous system and to the control of food intake and body weight. Am J Clin Nutr 42: Suppl 5: 1063-1071.

15. Schwartz MW, Woods SC, Seeley RJ, Barsh GS, Baskin 
DG, Leibel RL, 2003 Is the energy homeostasis system inherently biased toward weight gain? Diabetes 52: 232-238.

16. Ferrannini E, Natali A, Bell P, Cavallo-Perin P, Lalic N, Mingrone G, 1997 Insulin resistance and hypersecretion in obesity. J Clin Invest 100: 1166-1173.

17. Polyzogopoulou EV, Kalfarentzos F, Vagenakis AG, Alexandrides TK, 2003 Restoration of euglycemia and normal acute insulin response to glucose in obese subjects with type 2 diabetes following bariatric surgery. Diabetes 52: 1098-1103.

18. Camastra S, Gastaldelli A, Mari A, et al, 2011 Early and longer term effects of gastric bypass surgery on tissue-specific insulin sensitivity and beta cell function in morbidly obese patients with and without type 2 diabetes. Diabetologia 54: 2093-2102.

19. Lin E, Liang Z, Frediani J, et al, 2010 Improvement in $\beta$-cell function in patients with normal and hyperglycemia following Roux-en-Y gastric bypass surgery. Am J Physiol Endocrinol Metab 299: E706-E712.

20. Prager R, Wallace P, Olefsky J, 1986 In vivo kinetics of insulin action on peripheral glucose disposal and hepatic glucose output in normal and obese subjects. J Clin Invest 78: 472-481.

21. Prager R, Wallace P, Olefsky J 1987 Direct and indirect effects of insulin to inhibit hepatic glucose output in obese subjects. Diabetes 36: 607-611.

22. Basu R, Chandramouli V, Dicke B, Landau B, Rizza R, 2005 Obesity and type 2 diabetes impair insulin-induced suppression of glycogenolysis as well as gluconeogenesis. Diabetes 54: 1942-1948.

23. Chevalier S, Burgess S, Malloy C, Gougeon R, Marliss E, Morais J, 2006 The greater contribution of gluconeogenesis to glucose production in obesity is related to increased whole-body protein catabolism. Diabetes 55: 675-681.

24. Dimitriadis G, Newsholme E 2004 Integration of some biochemical and physiologic effects of insulin that may play a role in the control of blood glucose concentration. In: LeRoith D, Taylor S, Olefsky J (eds). Diabetes Mellitus, a fundamental and clinical text, Lippincott Williams and Wilkins: Philadelphia, Baltimore, New York, London, Buenos Aires, Hong Kong, Sydney, Tokyo; pp, 183-197.

25. Coppack S, Fisher R, Humphreys S, Clark M, Pointon J, Frayn K, 1996 Carbohydrate metabolism in insulin resistance: glucose uptake and lactate production by adipose tissue and forearm tissues in vivo before and after a mixed meal. Clin Sci 90: 409-415.

26. Bjorntorp P, Berchtold P, Holm J, Larsson B, 1971 The glucose uptake of human adipose tissue in obesity. Eur J Clin Invest 1: 480-485.

27. Baron A, Laakso M, Brechtel G, Hoit B, Watt C, Edelman S, 1990 Reduced postprandial skeletal muscle blood flow contributes to glucose intolerance in human obesity. $\mathrm{J}$ Clin Endocrinol Metab 70: 1525-1533.
28. Dimitriadis G, Lambadiari V, Mitrou P, et al, 2007 Impaired postprandial blood flow in adipose tissue may be an early marker of insulin resistance in type 2 diabetes. Diabetes Care 30: 3128-3130.

29. Friedman J, Lynis Dohm G, Leggett-Frazier N, et al, 1992 Restoration of Insulin Responsiveness in Skeletal Muscle of Morbidly Obese Patients after Weight Loss. Effect on Muscle Glucose Transport and Glucose Transporter GLUT4. J Clin Invest 89: 701-705.

30. Virtanen K, Lonnroth P, Parkkola R, et al, 2002 Glucose uptake and perfusion in subcutaneous and visceral adipose tissue during insulin stimulation in nonobese and obese humans. J Clin Endocrinol Metab 87: 3902-3910.

31. Laine, H, Yki-Järvinen H, Kirvelä O, et al, 1998 Insulin resistance of glucose uptake in skeletal muscle cannot be ameliorated by enhancing endothelium-dependent blood flow in obesity. J Clin Invest 101: 1156-1162.

32. Bickerton A, Roberts R, Fielding B, et al, 2007 Preferential uptake of dietary fatty acids in adipose tissue and muscle in the postprandial period. Diabetes 56: 168-176.

33. Mitrou P, Boutati E, Lambadiari V, et al, 2010 Rates of lipid fluxes in the adipose tissue in vivo after a mixed meal in women with morbid obesity. Int J Obes (Lond) 34: 770-774.

34. Reeds D, Stuart C, Perez O, Klein S, 2006 Adipose tissue, hepatic and skeletal muscle insulin sensitivity in extremely obese subjects with acanthosis nigricans. Metabolism 55: 1658-1663.

35. Riemens S, Sluiter W, Dullaart R, 2000 Enhanced escape of non-esterified fatty acids from tissue uptake: its role in impaired insulin-induced lowering of total rate of appearance in obesity and type II diabetes mellitus. Diabetologia 43: 416-426.

36. Gray R, Tanner C, Pories W, MacDonald K, Houmard J, 2003 Effect of weight loss on muscle lipid content in morbidly obese subjects Am J Physiol Endocrinol Metab 284: E726-E732.

37. Yu C, Chen Y, Cline G, et al, 2002 Mechanism by which fatty acids inhibit insulin activation of insulin receptor substrate-1 (IRS-1)-associated phosphatidylinositol 3-kinase activity in muscle. J Biol Chem 277: 50230-50236.

38. Houmard J, Tanner C, Yu C, et al, 2002 Effect of eight loss on insulin sensitivity and intramuscular long-chain fatty Acyl-CoAs in morbidly obese subjects. Diabetes 51: 2959-2963.

39. Greco A, Mingrone G, Giancaterini A, et al, 2002 Insulin resistance in morbid obesity. Reversal with intramyocellular fat depletion. Diabetes 251: 144-151.

40. Mingrone G, Rosa G, Di Rocco P, et al, 2002 Skeletal muscle triglycerides lowering is associated with net improvement of insulin sensitivity, TNF-a reduction and GLUT4 expression enhancement. Int J Obes 26: 1165-1172.

41. Verdelho Machado M, Ferreira D, Castro R, et al, 2012 Liver and muscle in morbid obesity: the interplay of fatty liver and insulin resistance PLoS ONE 7: e31738. 
42. Fain J, Madan A, Hiler M, Cheema P, Bahouth S, 2004 Comparison of the release of adipokines by adipose tissue, adipose tissue matrix and adipocytes from visceral and subcutaneous abdominal adipose tissue of obese humans. Endocrinology 145: 2273-2282.

43. Fain J, 2006 Release of interleukins and other inflammatory cytokines by human adipose tissue is enhanced in obesity and primarily due to nonfat cells. Vitam Horm 74: 443-477.

44. Fischer-Posovsky P, Wabitsch M, Hochberg Z, 2007 Endocrinology of adipose tissue - an update. Horm Metab Res 39:314-321.

45. Klover PJ, Zimmers TA, Koniaris LG, Mooney RA, 2003 Chronic exposure to interleukin-6 causes hepatic insulin resistance in mice. Diabetes 52: 2784-2789.

46. Senn JJ, Klover PJ, Nowak IA, Mooney RA, 2002 Interleukin-6 induces cellular insulin resistance in hepatocytes. Diabetes 51: 3391-3399.

47. Rotter V, Nagaev I, Smith U, 2003 Interleukin-6 (IL-6) induces insulin resistance in 3T3-L1 adipocytes and is, like IL-8 and tumour necrosis factor-alpha, overexpressed in human fat cells from insulin-resistant subjects. J Biol Chem 278: 45777-45784.

48. Carey AL, Steinberg GR, Macaulay SL, et al, 2006 Interleukin-6 increases insulin-stimulated glucose disposal in humans and glucose uptake and fatty acid oxidation in vitro via AMP-activated protein kinase. Diabetes 55: 2688-2697.

49. Al-Khalili L, Bouzakri K, Glund S, Lonnqvist F, Koistinen HA, Krook A, 2006 Signalling specificity of interleukin- 6 action on glucose and lipid metabolism in skeletal muscle. Mol Endocrinol 20: 3364-3375.

50. Pedersen BK, 2006 The anti-inflammatory effect of exercise: its role in diabetes and cardiovascular disease control. Essays Biochem 42: 105-117.

51. Chevrel G, Granet C, Miossec P, 2005 Contribution of tumour necrosis factor alpha and interleukin (IL) 1 beta to IL6 production, NF-kappa B nuclear translocation, and class $1 \mathrm{MHC}$ expression in muscle cells: in vitro regulation with specific cytokine inhibitors. Ann Rheum Dis 64: 1257-1262.

52. Mitrou P, Lambadiari V, Maratou E, et al, 2011 Skeletal muscle insulin resistance in morbid obesity: the role of intereukin-6 and leptin. Exp Clin Endocrinol Diabetes 119: 484-489.

53. Bruun J, Helge J, Richelsen B, Stallknecht B, 2006 Diet and exercise reduce low-grade inflammation and macrophage infiltration in adipose tissue but not in skeletal muscle in severely obese subjects. Am J Physiol Endocrinol Metab 290: E961-E967.

54. Carey AL, Bruce CR, Sacchetti M, et al, 2004 Interleukin-6 and tumor necrosis factor-alpha are not increased in patients with type 2 diabetes: evidence that plasma interleukin- 6 is related to fat mass and not insulin responsiveness. Diabetologia 47: 1029-1037.

55. Kern PA, Ranganathan S, Li C, Wood L, Ranganathan
G, 2001 Adipose tissue tumour necrosis factor and interleukin-6 expression in human obesity and insulin resistance. Am J Physiol 280: E745-E751.

56. Franckhauser S, Elias I, Rotter Sopasakis V, et al, 2008 Overexpression of IL-6 leads to hyperinsulinaemia, liver inflammation and reduced body weight in mice. Diabetologia 51: 1306-1316.

57. Zelissen P, Stenlof K, Lean M, et al, 2005 Effect of three treatment schedules of recombinant methionyl human leptin on body weight in obese adults: a randomized, placebo-controlled trial. Diabetes Obes Metab 7: 755-761.

58. Dyck DJ, 2009 Adipokines as regulators of muscle metabolism and insulin sensitivity. Appl Physiol Nutr Metab 34: 396-402.

59. Dyck DJ, Heigenhauser GJF, Bruce CR, 2006 The role of adipokines as regulators of skeletal muscle fatty acid metabolism and insulin sensitivity. Acta Physiologica 186: 5-16.

60. Mohamed-Ali V, Goodrick SJ, Rawesh A, et al, 1997 Subcutaneous adipose tissue releases interleukin-6, but not tumor necrosis factor- $\alpha$, in vivo. J Clin Endocrinol Metab 8: 4196-4200.

61. Hivert MF, Sullivan L, Fox C, et al, 2008 Associations of adiponectin, resistin, and tumor necrosis factor-alpha with insulin resistance. J Clin Endocrinol Metab 93: 3165-3172.

62. Ofei F, Hurel S, Newkirk J, Sopwith M, Taylor R, 1996 Effects of an engineered human anti-TNF- $\alpha$ antibody (CDP571) on insulin sensitivity and glycemic control in patients with NIDDM. Diabetes 45: 881-885.

63. Paquot N, Castillo M, Lefebre P, Scheen A, 2000 No increased insulin sensitivity after a single intravenous administration of a recombinant human tumor necrosis factor receptor: Fc fusion protein in obese insulin-resistant patients. J Clin Endocrinol Metab 85: 1316-1319.

64. Bullo M, Garcia-Lorda P, Peinado-Onsurbe J, et al, 2002 TNFa expression of subcutaneous adipose tissue in obese and morbid obese females: relationship to adipocyte LPL activity and leptin synthesis. Int J Obesity 26: 652-658.

65. Haseeb A, Iliyas M, Chakrabarti S, et al, 2009 Singlenucleotide polymorphisms in peroxisome proliferators activated receptor gamma and their association with plasma levels of resistin and the metabolic syndrome in a South Indian population. J Biosci 34: 405-414.

66. Asano H, Izawa H, Nagata K, et al, 2010 Plasma resistin concentration determined by common variants in the resistin gene and associated with metabolic traits in an aged Japanese population. Diabetologia 53: 234-246.

67. Beckers S, Peeters A, Freitas F, et al, 2008 Analysis of genetic variations in the resistin gene shows no associations in the resistin gene shows no associations with obesity in women. Obesity 16: 905-907.

68. Lee J, Chan J, Yiannakouris N, et al, 2003 Circulating resistin levels are not associated with obesity or insulin resistance in humans and are not regulated by fasting or leptin administration: cross-sectional and interventional 
studies in normal, insulin-resistant, and diabetic subjects. J Clin Endocrinol Metab 88: 4848-4856.

69. Curat C, Wegner V, Sengenes C, et al, 2006 Macrophages in human visceral adipose tissue: increased accumulation in obesity and a source of resistin and visfatin. Diabetologia 49: 744-747.

70. Savage D, Sewter C, Klenk E, et al, 2001 Resistin/ Fizz3 expression in relation to obesity and peroxisome proliferator-activated receptor-gamma action in humans. Diabetes 50: 2199-2202.

71. Motoshima H, Wu X, Sinha M, et al, 2000 Differential regulation of adiponectin secretion from cultured human omental and subcutaneous adipocytes: effects of insulin and rosiglitazone. J Clin Endocrinol Metab 87: 5662-5667.

72. Sabin M, Holly J, Shield J, et al, 2006 Mature subcutaneous and visceral adipocytes concentrations of adiponectin are highly correlated in prepubertal children and inversely related to body mass index standart deviation score. $\mathbf{J}$ Clin Endocrinol Metab 91: 332-335.

73. Bruun JM, Lihn AS, Verdich C, et al, 2003 Regulation of adiponectin by adipose tissue-derived cytokines: in vivo and in vitro investigations in humans. Am J Physiol
Endocrinol Metab 285: E527-E533.

74. Hu E, Liang P, Spiegelman BM, 1996 Adipo-q is a novel adipose-specific gene dysregulated in obesity. J Biol Chem 271: 10697-10703.

75. Arita Y, Kihara S, Ouchi N, et al, 1999 Paradoxical decrease of an adipose-specific protein, adiponectin, in obesity. Biochem Biophys Res Commun 257: 79-83.

76. Hotta K, Funahashi T, Arita Y, et al, 2000 Plasma concentrations of a novel, adipose-specific protein, adiponectin, in type 2 diabetic patients. Arter Thromb Vasc Biol 20: 1595-1599.

77. Statnick MA, Beavers LS, Conner LJ, et al, 2000 Decreased expression of apM1 in omental and subcutaneous adipose tissue of humans with type 2 diabetes. Int J Exp Diabetes Res 1:81-88.

78. Weyer C, Funahashi T, Tanaka S, et al 2001 Hypoadiponectinemia in obesity and type 2 diabetes: close association with insulin resistance and hyperinsulinemia. J Clin Endocrinol Metab 86: 1930-1935.

79. Kim J-Y, Wall E, Laplante M, et al, 2007 Obesityassociated improvements in metabolic profile through expansion of adipose tissue J Clin Invest 117: 2621-2637. 